\title{
8 Abkürzungsverzeichnis
}

\author{
ADB Historische Commission bei der Koeniglichen Akademie der \\ Wissenschaften (Hrsg.): Allgemeine Deutsche Biographie. Leipzig: \\ Duncker \& Humblot, 1896-1904. \\ BL Hirsch, A.: Biographisches Lexikon der hervorragenden Ärzte aller \\ Zeiten und Völker. München, Berlin: Urban und Schwarzenberg, \\ $1962^{3}$. \\ DBA Deutsches Biographisches Archiv. Zeitraum: bis Ende 19. \\ Jahrhundert (Microfiche). \\ GLA Generallandesarchiv Karlsruhe \\ HKA Heidelberger Klinische Annalen. Heidelberg: Mohr, 1825-1834 \\ MA Medicinische Annalen. Heidelberg: Mohr, 1835-1848 \\ NDB Historische Kommission bei der Bayerischen Akademie der \\ Wissenschaft (Hrsg.): Neue deutsche Biographie. Berlin: Duncker \\ PA Personalakten \\ UA Universitătsarchiv Heidelberg
}

